\title{
Resistência ao Impacto e Outras Propriedades de Compósitos Lignocelulósicos: Matrizes Termofixas Fenólicas Reforçadas com Fibras de Bagaço de Cana-de-açúcar
}

\author{
Sandra P. S. Tita, Jane M. F. de Paiva, Elisabete Frollini \\ Instituto de Química de São Carlos, USP
}

Resumo: Pré-polímeros fenólicos e lignofenólicos (substituição de 40\% em massa de fenol por lignina, extraída do bagaço de cana) foram sintetizados para preparar compósitos com matrizes termofixas, usando bagaço de cana-de-açúcar como agente de reforço. Este material lignocelulósico foi modificado por métodos químicos e/ ou físicos (tratamento com álcali, esterificação, ar ionizado). O bagaço de cana promoveu pequeno aumento na resistência ao impacto das matrizes fenólica e lignofenólica. Os métodos de tratamento de superfície melhoraram a dispersão das fibras na matriz assim como a adesão entre ambas as resinas, fenólica e lignofenólica, e as fibras lignocelulósicas. Apenas os compósitos tratados com ar ionizado mostraram melhores resultados de resistência ao impacto. Em relação à absorção de água, foi observado que os compósitos fenólicos reforçados com fibras tratadas com $8 \% \mathrm{NaOH}$ apresentaram uma menor absorção de água. Quanto aos compósitos lignocelulósicos, os reforçados com fibras esterificadas apresentaram uma menor absorção de água.

Palavras-chave: Fibra vegetal, bagaço de cana-de-açúcar, matriz termofixa, compósitos fenólicos, resistência ao impacto, lignina.

\section{Impact Strength and Other Properties of Lignocellulosic Composites: Phenolic Thermoset Matrices Reinforced with Sugarcane Bagasse Fibers}

Abstract: Phenolic and lignophenolic (40\% sugarcane bagasse lignin/phenol w/w) pre-polymers were synthesized to produce thermoset matrices composites, using sugarcane bagasse as reinforcing agent. This lignocellulosic material was modified by chemical and/or physical methods (alkali treatment, esterification, ionized air). Sugarcane bagasse showed a small improvement in impact strength for both phenolic and lignophenolic matrices. The surface treatment methods improved dispersion as well as adhesion between the resins, phenolic and lignophenolic, and lignocellulosic fibers, but only the composites treated with ionized air exhibited better impact strength results. Concerning the water uptake, for the phenolic composites it was observed that the one reinforced with fibers treated with $8 \% \mathrm{NaOH}$ presented a smaller water uptake. For the lignophenolic composites, that reinforced with fibers esterified during $24 \mathrm{hr}$, using succinic anhydride, presented the lower water uptake.

Keywords: Vegetal fiber, sugarcane bagasse, thermoset matrix, phenolic composites, impact strength, lignin.

\section{Introdução}

É crescente o interesse na utilização de materiais lignocelulósicos, principalmente de fibras vegetais (sisal, juta, coco, banana, curauá) $)^{[1-3]}$, como reforço em compósitos de matriz termofixa e/ou termoplás- tica. Estes compósitos podem ser aplicados em diversas áreas, desde a indústria automotiva ${ }^{[4]}$, embalagens até a de construção civil ${ }^{[5,6]}$. O interesse por estes compósitos está relacionado às propriedades e características das fibras vegetais, podendo-se destacar baixo custo, baixa densidade, flexibilidade no

Autor para correspondência: Elisabete Frollini, Instituto de Química de São Carlos, USP, Caixa Postal 780, CEP: 13560-970, São Carlos, SP. E-mail: elisabete@iqsc.sc.usp.br 
processamento e uso de sistemas simples quando o tratamento de superfície é necessário ${ }^{[7,8]}$. Além disso, as fibras vegetais são fontes renováveis, amplamente distribuídas, disponíveis, moldáveis, não-abrasivas, porosas, viscoelásticas, biodegradáveis, combustíveis e reativas ${ }^{[9]}$. Quanto à reatividade química, estas fibras lignocelulósicas apresentam grupos hidroxila acessíveis, podendo reagir com outros grupos funcionais polares, como por exemplo, os presentes nas resinas fenólicas ${ }^{[10]}$.

As resinas fenólicas exibem estabilidade dimensional, estabilidade térmica e resistência química a temperaturas elevadas. Entretanto, a alta densidade de entrecruzamento, após a cura, resulta em baixa resistência à fratura, tornando as resinas fenólicas mais frágeis quando comparadas a muitos outros plásticos, o que impede a aplicação destas em alguns ca$\operatorname{sos}^{[11]}$. Assim, para melhorar a resistência ao impacto, torna-se necessário o reforço dessas matrizes, o que resulta em compósitos.

A estrutura e natureza da interface fibra-matriz desempenha um papel importante nas propriedades mecânicas e físicas dos materiais compósitos, porque é através desta interface que ocorre a transferência de carga da matriz para a fibra ${ }^{[12]}$. Para otimizar a interface, muitos métodos físicos e químicos, com diferentes eficiências, costumam ser utilizados, com o principal objetivo de intensificar a adesão entre a fibra e a matriz $^{[6]}$. Dentre estes, pode-se destacar a modificação química da fibra por reações químicas, com a utilização de agentes de acoplamento para modificar a natureza química da fibra, que posteriormente irá interagir com a matriz polimérica. Os métodos físicos de modificação da fibra mais conhecidos são: plasma e descarga elétrica (corona, ar ionizado) ${ }^{[6,13]}$.

Considerando-se que o bagaço de cana-de-açúcar proveniente das usinas de álcool e açúcar ${ }^{[14]}$ é originário de fonte renovável, estudos vêm se desenvolvendo no sentido de utilizar a lignina (extraída do bagaço) na preparação de outros materiais ${ }^{[1,2]}$. Os anéis fenólicos presentes na estrutura complexa da lignina permitem a sua utilização como substituinte parcial do fenol, o qual é empregado em sínteses de resinas fenólicas, pois a lignina pode reagir com o formaldeído ${ }^{[1,2,15,16]}$.

A lignina presente no bagaço de cana-de-açúcar contém uma maior proporção de anéis aromáticos do tipo $p$-hidroxifenila, com relação a anéis do tipo guaiacila e siringila, comparando-se com outras fon- tes como, por exemplo, a madeira. Observa-se, nestas unidades, que as posições 3 e 5 do anel aromático estão desimpedidas, fazendo com que estes anéis aromáticos sejam mais reativos ${ }^{[17,18]}$. Por estes motivos, a lignina extraída do bagaço de cana-de-açúcar é adequada para ser utilizada como substituinte parcial do fenol na produção de resinas fenólicas ${ }^{[19]}$.

Visando o aproveitamento de recursos naturais (produtos e subprodutos agrícolas, tais como lignina e bagaço de cana), buscando-se alternativas que sejam economicamente viáveis para o reforço de matrizes fenólicas, realizou-se moldagens de compósitos de matrizes fenólica e lignofenólica reforçadas com fibras de bagaço de cana-de-açúcar, não tratadas, assim como submetidas a diferentes tratamentos físicos e químicos.

\section{Experimental}

\section{Preparação e Modificações das Superfícies dos Materiais Lignocelulósicos}

As fibras de bagaço de cana (gentilmente cedidas pela Copersucar - Piracicaba/SP) foram desmeduladas e a seguir foram extraídas (soxhlet) com cicloexano/etanol (1:1, v:v) por $48 \mathrm{~h}$. Posteriormente, as fibras foram submetidas a extração com água destilada por $24 \mathrm{~h}$ a $70{ }^{\circ} \mathrm{C}$. Em seguida, estas fibras extraídas, foram secas em estufa com circulação de ar. Foram feitos tratamentos nas fibras de bagaço de cana com soluções 2, 4, 6, 8 e $10 \%$ de $\mathrm{NaOH}$ por $1 \mathrm{~h}$, a $0{ }^{\circ} \mathrm{C}$. Esta temperatura foi escolhida a fim de minimizar a degradação dos componentes das fibras; a concentração de $\mathrm{NaOH}$ foi diversificada com o objetivo de se avaliar a influência deste parâmetro nas propriedades das fibras e, conseqüentemente, nas propriedades dos compósitos reforçados com as mesmas. Após o tratamento, as fibras foram lavadas exaustivamente com água destilada e filtradas, até se observar pH igual ao da água de lavagem pura, sendo em seguida secas. As fibras de bagaço de cana tratadas com solução $10 \%$ de $\mathrm{NaOH}$ também foram submetidas à reações de esterificação com anidrido succínico (solução saturada em xileno), por 24, 36 e $48 \mathrm{~h}$. Os tempos de reação foram escolhidos a partir de resultados de trabalhos anteriores ${ }^{[1]}$, assim como de dados encontrados na literatura ${ }^{[10]}$. Após as reações, as fibras foram lavadas exaustivamente com água destilada e secas. Reações das fibras de bagaço de 
cana com lignina/formaldeído (1:4,36 em massa) em diferentes tempos de reação (15, 30 e $60 \mathrm{~min})$, foram realizadas como um terceiro tipo de modificação química das superfícies das fibras, a temperatura de $70{ }^{\circ} \mathrm{C}$, sob refluxo. Nestas reações, utilizou-se meio alcalino (solução de $\mathrm{KOH}, \mathrm{pH}$ 9) e seguiu-se os mesmos procedimentos de lavagem e secagem das fibras descritos anteriormente. Os tempos de reação foram significativamente menores que aqueles usados nas reações de esterificação, pois é conhecido que o meio alcalino pode degradar os componentes de fibras lignocelulósicas, principalmente a uma temperatura de $70{ }^{\circ} \mathrm{C}^{[2,6]}$. As fibras extraídas foram submetidas ainda a tratamento com ionizador de ar elétrico (corrente máxima de $5 \mathrm{~mA}$, voltagem de $7,5 \mathrm{kV}$ ) por $1 \mathrm{~h}$, em um sistema fechado, contendo bicos injetores de ar (SIMCO).

\section{Preparação dos Pré-polímeros}

O pré-polímero fenólico (resol) foi obtido reagindo fenol, formaldeído e hidróxido de potássio (1,38:1,0:0,06 - em massa) com agitação mecânica sob refluxo $\left(70{ }^{\circ} \mathrm{C}\right)$ por $1 \mathrm{~h}$. Após a reação, o meio reacional foi neutralizado com $\mathrm{HCl}$ concentrado e, posteriormente, destilou-se a água sob pressão reduzida. Sintetizouse também o pré-polímero lignofenólico, sendo que neste caso substituiu-se o fenol parcialmente (40\% em massa) por lignina (extraída do bagaço de cana pelo processo organossolve, acetona em meio ácido), gentilmente cedida pelas indústrias Dedini S.A. e Copersucar, Piracicaba-SP ${ }^{[1,2,20]}$.

\section{Obtenção dos Termofixos e Compósitos}

As moldagens foram realizadas por compressão (usando-se uma prensa de laboratório), em molde portátil, com dimensões de $(230,0 \times 120,0 \times 5,0) \mathrm{mm}$, até atingir 3,6 MPa. Os ciclos de cura seguidos durante as moldagens (para os termofixos fenólicos: $75^{\circ} \mathrm{C}$ por $1 \mathrm{~h} ; 85^{\circ} \mathrm{C}$ por $1,5 \mathrm{~h} ; 95^{\circ} \mathrm{C}$ por $0,5 \mathrm{~h} ; 105^{\circ} \mathrm{C}$ por $0,5 \mathrm{~h} ; 115^{\circ} \mathrm{C}$ por $1 \mathrm{~h} \mathrm{e} 125^{\circ} \mathrm{C}$ por $1,5 \mathrm{~h}$ - para os termofixos lignofenólicos: $75^{\circ} \mathrm{C}$ por $1 \mathrm{~h} ; 85^{\circ} \mathrm{C}$ por $1 \mathrm{~h} ; 100^{\circ} \mathrm{C}$ por $1 \mathrm{~h}$ e $125^{\circ} \mathrm{C}$ por $2 \mathrm{~h}$ ) foram préestabelecidos por análises de DSC (Differential Scanning Calorimetry ${ }^{[20]}$. Em todos os compósitos reforçados com fibras de bagaço (comprimento médio de $1,5 \mathrm{~cm}, 70 \% \mathrm{v}: \mathrm{v})$ desmeduladas em uma etapa anterior. Para tornar mais viável a ocorrência de reações entre os grupos hidroxílicos presentes nas fibras e os grupos hidroximetila dos pré-polímeros (fenólico e lignofenólico), foram feitas impregnações prévias das fibras (modificadas ou não) com estes pré-polímeros, a aproximadamente $50^{\circ} \mathrm{C}$, sob agitação mecânica, por $30 \mathrm{~min}$, antes da etapa de cura. Adicionou-se ainda resorcinol (acelerador de cura - $10 \%$ em massa) ${ }^{[20,21]}$.

\section{Caracterizações}

\section{Fibras}

\section{a) Teor de Lignina Klason}

Para determinar os teores de lignina Klason totais nas fibras de bagaço de cana tratadas ou não, utilizou-se o método TAPPI T13 m-54 modificado e $\operatorname{adaptado}^{[14]}$.

\section{b) Teor de Holocelulose}

Os teores de holocelulose (celulose + hemicelulose) nas fibras de bagaço de cana, tratadas ou não, foram determinados de acordo com o método TAPPI T19m-54. Na seqüência, utilizando-se amostras de holocelulose da etapa anterior, foram determinados os teores de celulose e por diferença obteve-se os teores de hemicelulose.

\section{c) Teor de $\alpha$-celulose}

Foram adicionados $10 \mathrm{~mL}$ de solução de $\mathrm{NaOH}$ $(17,5 \%)$ à $1,0 \mathrm{~g}$ de celulose. Deixou-se em repouso por 2 min. e, em seguida, triturou-se por $8 \mathrm{~min}$. Foram acrescentados mais $10 \mathrm{~mL}$ de solução de $\mathrm{NaOH}$, misturou-se bem e deixou-se em repouso por $20 \mathrm{~min}$. Adicionou-se $40 \mathrm{~mL}$ de água e filtrou-se em cadinho sinterizado de porosidade média. O resídou sólido foi lavado com ácido acético diluído e água e seco a princípio em estufa de circulação à $105^{\circ} \mathrm{C}$ e, em seguida, em estufa a vácuo à $50^{\circ} \mathrm{C}$, até massa constante. $\mathrm{O}$ teor de $\alpha$-celulose foi calculado pela relação percentual entre a massa de celulose antes e após a extração das hemiceluloses com solução de $\mathrm{NaOH}$ 17,5 \%.

\section{Polímeros}

\section{a) Ensaio de Impacto}

Os ensaios de impacto Izod foram realizados de acordo com a norma ASTM D256 $6^{[22]}$, usando-se dez corpos de prova, utilizando-se o equipamento CEAST Resil 25 com martelo instrumentado, a temperatura ambiente, velocidade de impacto de $3,46 \mathrm{~m} / \mathrm{s}$ e pêndulos com energias de impacto de 2,75 e 5,5 J. 


\section{b) Microscopia Eletrônica de Varredura (MEV)}

Após os ensaios de impacto, foram realizadas análises das fraturas por MEV (Microscopia Eletrônica de Varredura) utilizando-se microscópio LEO da marca ZEISS-LEICA modelo 440, voltagem de aceleração de $20 \mathrm{keV}$.

\section{c) Absorção de Água}

Os polímeros também foram submetidos ao ensaio de absorção de água (em duplicatas), sendo o mesmo realizado segundo a norma ASTM D570[23].

\section{Resultados e Discussão}

\section{Modificação das Fibras}

\section{a) Modificação com Anidrido Succínico}

A reação de esterificação entre a fibra e o anidrido succínico, leva a uma modificação química que pode ser esquematizada como mostrado na Figura 1. Os grupos hidroxílicos podem pertencer à celulose, à lignina ou à hemicelulose ${ }^{[10]}$.

Durante a reação, ocorre a abertura do anel do anidrido succínico originando um grupo $-\mathrm{COOH}, \mathrm{o}$ qual pode interagir via ligações de hidrogênio com outro grupo - $\mathrm{OH}$ da celulose da fibra, ou com uma hidroxila da matriz fenólica, quando faz parte do compósito. A reação de esterificação foi confirmada pela presença da banda relacionada à carbonila de ésteres, em torno de $1730 \mathrm{~cm}^{-1}$, no espectro de infravermelho obtido (figura não mostrada).

\section{b) Modificação com Lignina/Formaldeido e Tra-} tamento com Soluções de $\mathrm{NaOH}$

A lignina reage com formaldeído, através do ataque eletrofílico deste às posições livres dos anéis aromáticos da lignina. Em meio alcalino, a desprotonação

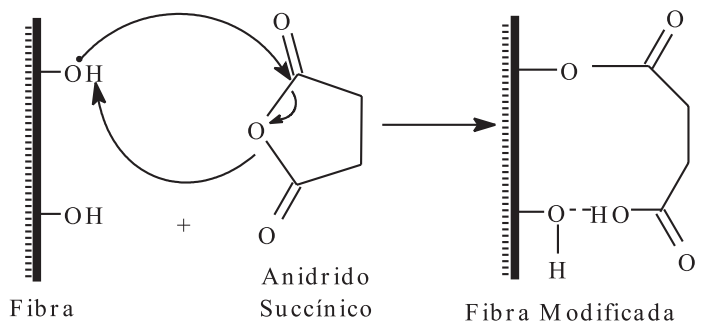

Figura 1. Representação esquemática da modificação química das fibras de bagaço de cana com anidrido succínico, mostrando uma ligação de hidrogênio entre os grupos carboxílico e hidroxila. da hidroxila fenólica ativa o ataque do eletrófilo ${ }^{[16,24,25]}$. Nestas reações, grupos hidroximetila são introduzidos na macromolécula de lignina resultando no aumento da reatividade da mesma ${ }^{[16,26]}$. Esta lignina ativada, uma vez colocada em contato com a fibra lignocelulósica, pode reagir com os componentes das fibras lignocelulósicas como, por exemplo, com a celulose ou a própria lignina ${ }^{[25]}$.

Na Figura 2 está mostrada uma representação esquemática da modificação química das fibras lignocelulósicas, quando estas reagem com lignina hidroximetilada.

Se a reação ocorre, tem-se então uma fibra lignocelulósica com sua superfície "enriquecida" de frações típicas da molécula de lignina. Sabe-se que a lignina participa de reações com fenol, sendo inclusive usada como substituta parcial do fenol na preparação de resinas fenólicas ${ }^{[1,2,18]}$, como no presente trabalho. Assim, a introdução de lignina na superfície da fibra pode facilitar reações fibra/matriz, durante a etapa de moldagem, levando a uma maior adesão nesta região. A introdução dos anéis aromáticos hidrofóbicos na superfície deve ainda dificultar a absorção de água por parte do compósito.

A Figura (3.a) mostra o gráfico com os resultados dos teores totais de lignina Klason, obtidos para o bagaço de cana-de-açúcar, em função do tempo de reação com lignina hidroximetilada. Nas fibras de bagaço de cana-de-açúcar modificadas considerando-se o tempo reacional de1h, observa-se que o teor de lignina foi maior em relação às fibras modificadas por 15 e $30 \mathrm{~min}$. Isto sugere uma reação de modificação em maior extensão no intervalo de $1 \mathrm{~h}$.

Ainda, os resultados mostrados na Figura (3.a), considerando-se um tempo reacional de $15 \mathrm{~min}$, indicam que não houve acréscimo no teor de lignina

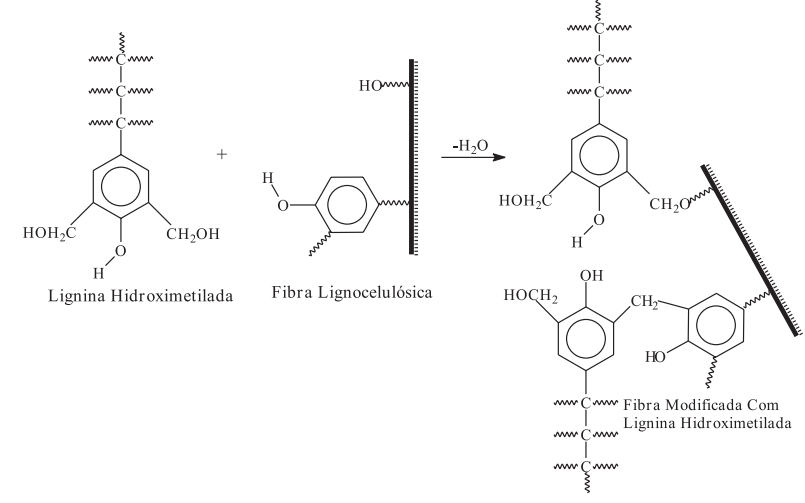

Figura 2. Representação esquemática da modificação química das fibras lignocelulósicas via reação com lignina hidroximetilada. 


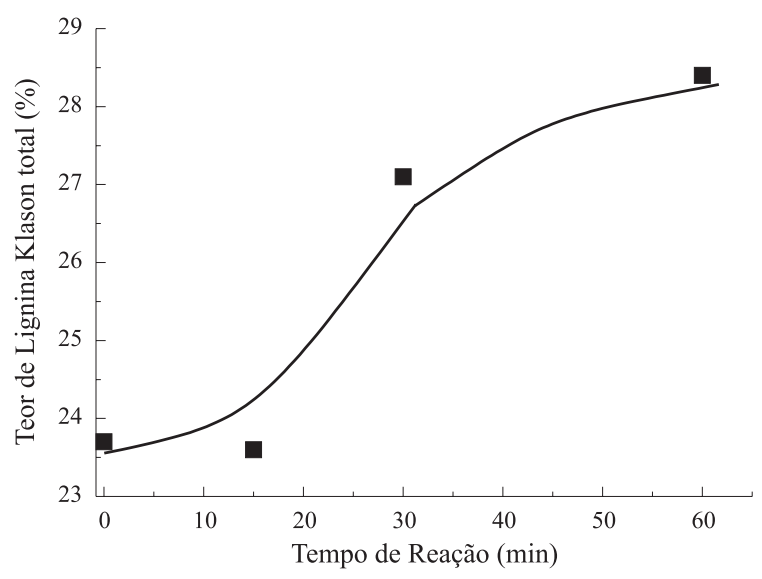

(a)

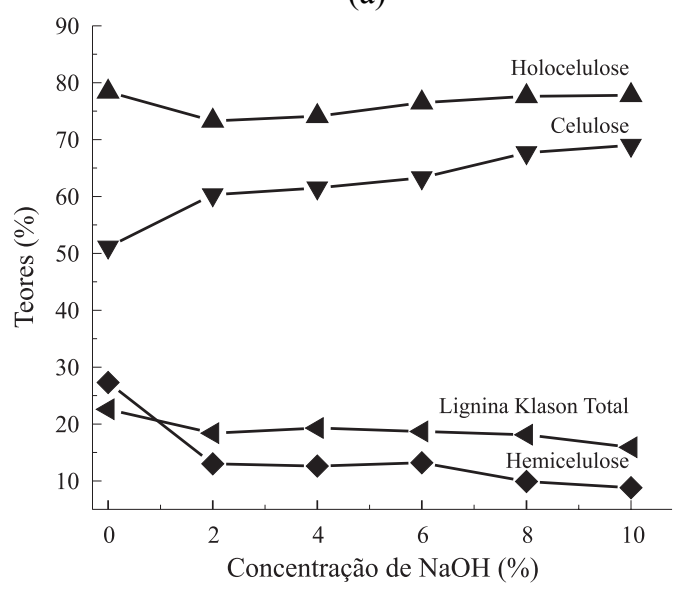

(b)

Figura 3. (a) Teor de lignina Klason total em função do tempo de reação das fibras de bagaço de cana-de-açúcar com lignina hidroximetilada e (b) variação nos teores dos constituintes das fibras de bagaço de cana em função da concentração da solução de $\mathrm{NaOH}$.

para o bagaço de cana. Deve-se ressaltar que, como estas reações foram realizadas em meio alcalino, a $70{ }^{\circ} \mathrm{C}$, deve ter ocorrido extração de lignina, para todos os tempos de reação considerados. Assim, o conteúdo de lignina, determinado para a fibra após a reação, não necessariamente reflete a quantidade desta macromolécula que reagiu com a superfície da fibra.

$\mathrm{Na}$ Figura (3.b) estão mostradas as variações nos teores dos constituintes das fibras em função da concentração da solução de $\mathrm{NaOH}$, usada durante o tratamento alcalino das fibras. Sabe-se que as hemiceluloses são facilmente solubilizadas em meio alcalino $^{[6,14,27]}$, o que pode ser comprovado pela Figura (3.b) na qual se observam as reduções nos teores de hemicelulose após os tratamentos com as soluções de $\mathrm{NaOH}$, principalmente quando se utilizou as soluções 8 e $10 \%$. Os resultados também revelam que, após os tratamentos, os menores teores de lignina Klason totais foram aqueles obtidos para as amostras de bagaço de cana-de-açúcar tratadas com as soluções 8 e $10 \%$ de $\mathrm{NaOH}$. Como conseqüências das remoções de frações oligoméricas de lignina e de hemicelulose, verificou-se um aumento nos teores de celulose nas fibras de bagaço de cana com o aumento da concentração da solução de $\mathrm{NaOH}$. Os teores de holocelulose (celulose + hemicelulose) não apresentaram mudanças significativas, devido a compensação entre os aumentos dos teores de celulose e, principalmente, as diminuições dos teores de hemicelulose, em função do aumento da concentração da solução alcalina.

\section{Resistência ao Impacto}

Os resultados mostrados nas Figuras (4.a) e (6.a) indicam que os valores de resistência ao impacto dos termofixos fenólico (TF) e lignofenólico (TLig) foram muito próximos, 12,8 e 13,3 J/m respectivamente, ou seja, a substituição parcial do fenol por lignina pode ser feita sem prejuízos para esta propriedade. Na Figura (5.a), observa-se também que a resistência ao impacto do compósito fenólico, com fibras não tratadas, apresenta resistência ao impacto superior a do termofixo, mostrando que as fibras atuam como reforço na matriz.

Embora os desvios-padrão aproximem os valores de resistência ao impacto dos compósitos reforçados com fibras tratadas com diferentes concentrações de $\mathrm{NaOH}$ (Figura 4.b), nota-se uma tendência de diminuição da resistência, até $8 \% \mathrm{de} \mathrm{NaOH}$. Isto provavelmente é uma indicação da maior fragilidade destas fibras, causada pela maior remoção de frações de alguns dos componentes destas (lignina e hemicelulose, Figura 3.b) com o aumento da concentração da solução de $\mathrm{NaOH}$ usada nos tratamentos. No caso do compósito contendo bagaço tratado com solução $10 \%$ de $\mathrm{NaOH}$, verificou-se uma tendência de aumento na resistência ao impacto, com valor médio em torno de $22 \mathrm{~J} / \mathrm{m}$, quando comparado com os compósitos reforçados com fibras de bagaço de cana tratadas nas demais concentrações. Pode-se observar ainda que os compósitos reforçados com estas fibras apresentaram o menor desvio-padrão. $\mathrm{O}$ tratamento das fibras com a solução $10 \%$ de $\mathrm{NaOH}$, levou a uma maior separação dos feixes de fibras (observado pela análise realizada por Microscopia Eletrônica de Varredura), o que por sua vez deve ter propiciado uma distribuição mais homogênea das fibras na matriz, 


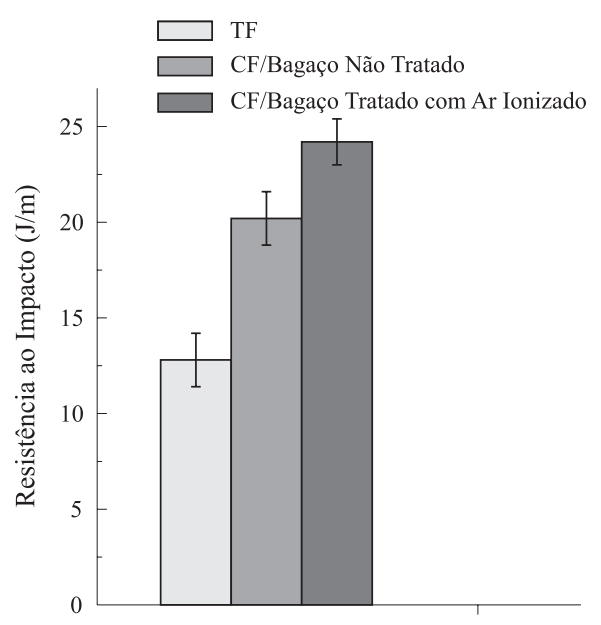

(a)

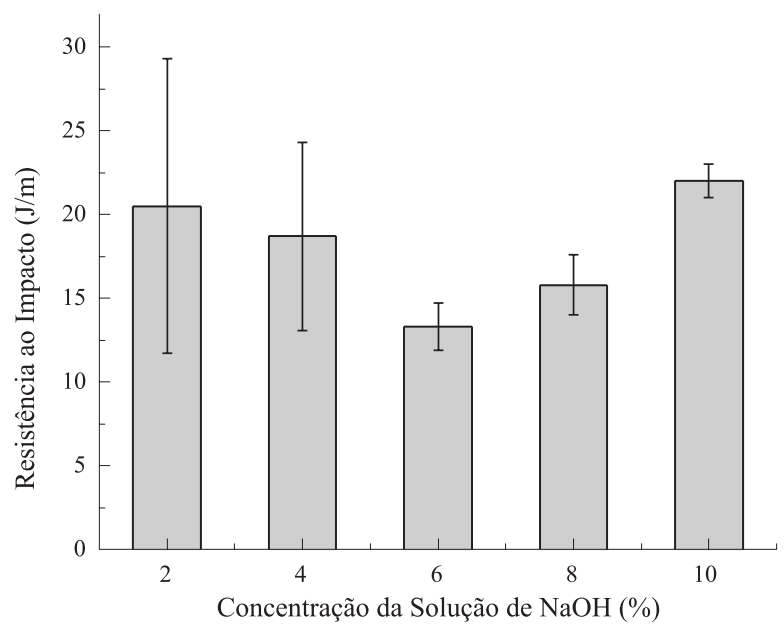

(b)

Figura 4. Resultados dos ensaios de impacto, sendo: (a) referente ao termofixo fenólico sem fibras (TF) e aos compósitos fenólicos (CF) reforçados com fibras de bagaço de cana não tratadas e com fibras de bagaço de cana tratadas com ar ionizado; (b) referente aos compósitos fenólicos reforçados com fibras de bagaço de cana tratadas com diferentes concentrações de soluções de $\mathrm{NaOH}$.

em relação às outras concentrações das soluções de $\mathrm{NaOH}$ estudadas. Portanto, tem-se uma indicação de que o tratamento com solução $10 \%$ de $\mathrm{NaOH}$ ocasionou uma desagregação mais eficiente dos feixes de fibras, aumentou a molhabilidade e pode ter promovido uma melhor interdifusão do pré-polímero sobre as fibras durante o processo de mistura, ocasionando uma maior interação entre fibras e matriz ${ }^{[28]}$.

Considerando que a fração de celulose é muito importante na definição da propriedade mecânica da fibra, eventuais degradações das cadeias de celulose levam a uma pior atuação como agente de reforço ${ }^{[29]}$.

Os valores das resistências ao impacto, referentes aos compósitos fenólicos, mostrados nas Figuras

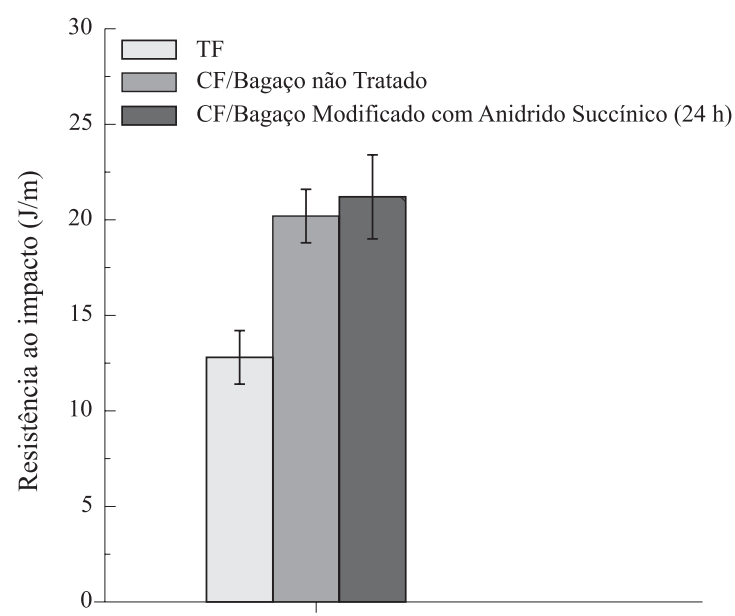

(a)

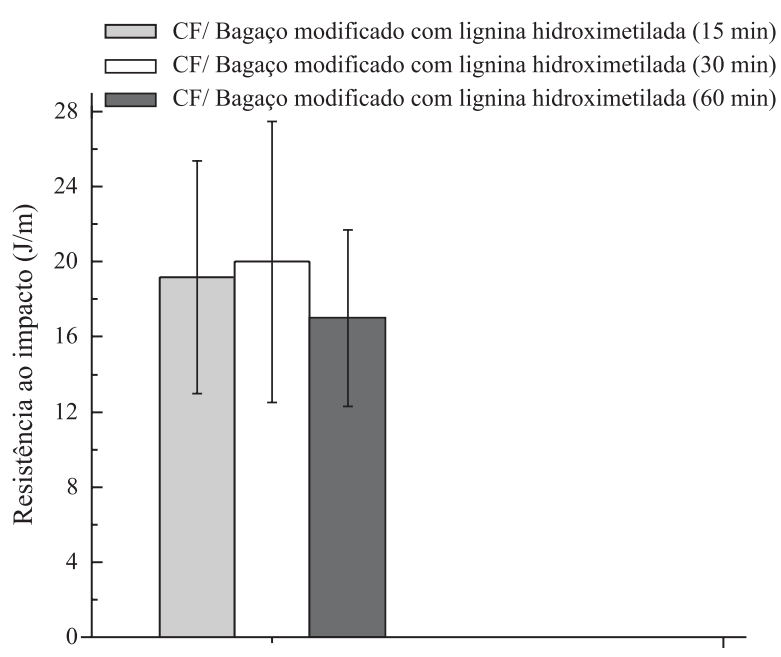

(b)

Figura 5. Resultados dos ensaios de impacto, sendo: (a) referente ao termofixo fenólico sem fibras (TF) e aos compósitos fenólicos (CF) reforçados com fibras de bagaço de cana apenas extraídas e com fibras de bagaço de cana modificadas com anidrido succínico (24 h); (b) referente aos compósitos fenólicos reforçados com bagaço de cana modificado com lignina hidroximetilada em diferentes tempos de reação.

$5(a$ e $b)$, revelam que as modificações químicas dos feixes de fibras de bagaço de cana com anidrido succínico ( $24 \mathrm{~h}$ de reação) ou com lignina hidroximetilada (em diferentes tempos de reação), não proporcionaram incrementos nesta propriedade mecânica, quando comparadas com a resistência ao impacto do compósito com fibras não modificadas.

Comparando-se os resultados dos compósitos contendo fibras não tratadas e os dos compósitos com fibras tratadas, observa-se que, assim como o compósito fenólico (Figura 4.b) o lignofenólico contendo bagaço tratado com solução $10 \%$ de $\mathrm{NaOH}$ (Figura 6.a), também apresentou uma tendência de 


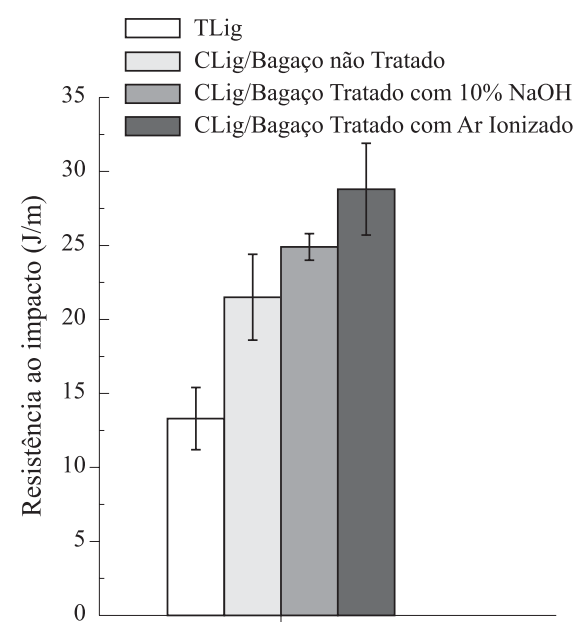

(a)

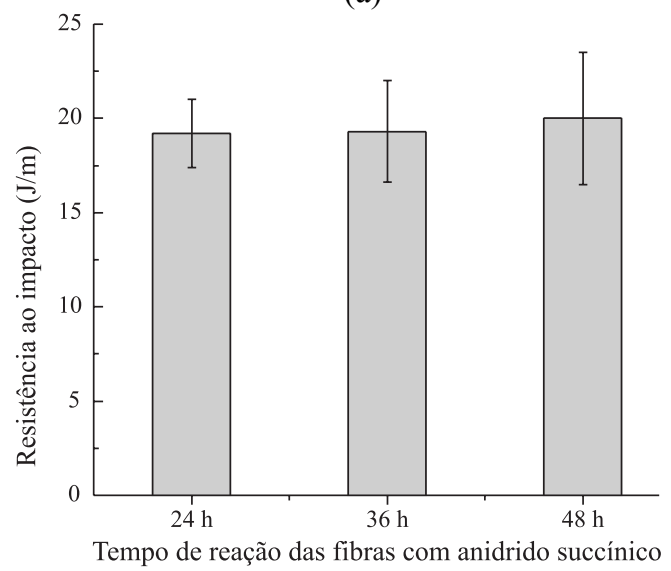

(b)

Figura 6. Resultados dos ensaios de impacto, sendo: (a) referente ao termofixo lignofenólico sem fibras (TLig) e aos compósitos lignofenólicos (CLig) reforçados com fibras de bagaço de cana apenas extraídas, com fibras de bagaço de cana tratadas com $10 \% \mathrm{NaOH}$ e com fibras de bagaço ionizadas; (b) referente aos compósitos lignofenólicos com fibras de bagaço de cana tratadas com solução $10 \%$ de $\mathrm{NaOH}$ esterificadas por 24,36 e $48 \mathrm{~h}$.

aumento na resistência ao impacto, com relação ao compósito reforçado com fibra não tratada. Observase, também, no compósito lignofenólico, que este tratamento leva a uma distribuição mais homogênea das fibras, conforme indicado pelo menor desvio padrão observado.

Os compósitos fenólicos (Figura 4.a) e lignofenólicos (Figura 6.a) contendo bagaço tratado com ar ionizado apresentaram acréscimo nos valores da resistência ao impacto, em relação aos respectivos compósitos contendo bagaço sem tratamento.

Entre todos os compósitos reforçados com bagaço (Figuras 4, 5 e 6), no que se refere à resistência ao impacto, destaca-se o compósito lignofenólico/bagaço tratado com ar ionizado, pois o mesmo apresentou um aumento de cerca de $34 \%$ em relação ao compósito lignofenólico/bagaço sem tratamento. $\mathrm{O}$ compósito fenólico/bagaço tratado com ar ionizado também apresentou um aumento significativo de cerca de $20 \%$ no valor da resistência ao impacto. Foi observado por MEV (Microscopia Eletrônica de Varredura) que o tratamento utilizando ar ionizado separou os feixes de fibras, possibilitando maior área de contato das fibras com o pré-polímero durante a etapa de impregnação e levando, posteriormente, a uma interação fibra-matriz mais intensa.

No geral, a esterificação da fibra não melhorou a resistência ao impacto, tanto para a matriz fenólica como para a lignofenólica. Apesar do tratamento com anidrido succínico ter ocasionado modificação química nas fibras, esta modificação provocou danos aos feixes de fibras, pois estes se tornaram mais frágeis mecanicamente. Visualmente e ao contato manual com as fibras, observou-se que o bagaço de cana, após esterificação, apresentou-se mais frágil. Provavelmente, as frações de lignina que foram extraídas durante a reação contribuíram para este efeito.

\section{Microscopia Eletrônica de Varredura (MEV)}

O comportamento da fratura em compósitos é afetado por muitas variáveis, incluindo a natureza da fibra e da matriz, a interação fibra-matriz, a orientação das fibras, a quantidade de vazios na matriz, a carga e $\mathrm{o}$ ambiente a que foram submetidas as amostras. $\mathrm{O}$ estudo da fratura através da MEV pode revelar áreas nas quais ocorreram algumas das possíveis falhas em compósitos, tais como trincas na matriz e falha de ligação interfacial entre matriz e fibra ${ }^{[30]}$.

A extração de hemiceluloses e lignina por soluções alcalinas, provoca modificações na composição química das fibras e como consequência a parede celular parece estratificada, ou seja, com várias camadas. As mudanças químicas começam a ser significativas quando se realiza tratamento com soluções mais concentradas e desta forma a parede celular sofre severas alterações estruturais ${ }^{[31]}$. Em compósitos poliméricos reforçados com fibras vegetais, estas mudanças estruturais influenciam no interpenetramento da matriz polimérica nas regiões mais internas dos feixes de fibras, melhorando a adesão fibra-matriz, o que pode resultar no aumento da resistência ao impacto.

As fotomicrografias mostradas na Figuras 7 são correspondentes às fraturas dos compósitos fenólicos 


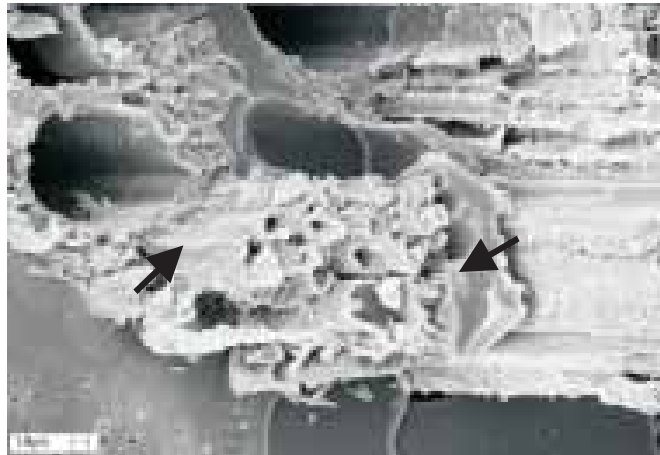

aumento $1000 \mathrm{X}$

(a)

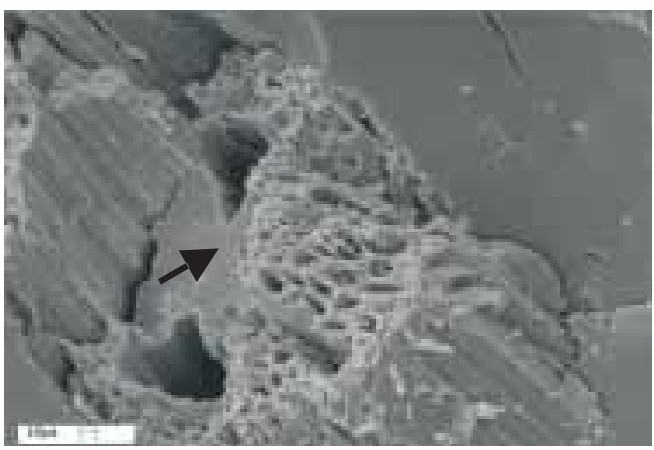

aumento $1000 \mathrm{X}$

(b)

Figura 7. Fotomicrografias das superfícies de fratura dos compósitos fenólicos reforçados com bagaço: (a) fibras apenas extraídas com cicloexano/etanol e (b) fibras tratadas com solução $6 \%$ de $\mathrm{NaOH}$.

contendo bagaço de cana não tratado e submetido a tratamento com solução alcalina.

Observando a fotomicrografia do compósito fenólico com fibras de bagaço tratado com solução $6 \%$ de $\mathrm{NaOH}$ (Figura 7.b), verifica-se que a matriz interpenetrou melhor nos feixes de fibras (ver seta), indicando desagregação parcial das fibras presentes no feixe tratado com $\mathrm{NaOH}$ e melhor adesão fibramatriz, quando comparadas com as fibras presentes na superfície de fratura do compósito fenólico mostrado na Figura (7.a).

O mesmo pode ser verificado para o compósito lignofenólico com fibras submetidas ao tratamento com solução $10 \%$ de $\mathrm{NaOH}$ (fotomicrografias não mostradas).

A adesão fibra-matriz também foi melhorada nos compósitos fenólico e lignofenólico reforçados com fibras tratadas com ar ionizado (ver setas, Figura 8).

No geral, pode-se observar que praticamente todos os compósitos fenólicos e lignofenólicos apresentaram adesão entre fibras e matriz, com destaque

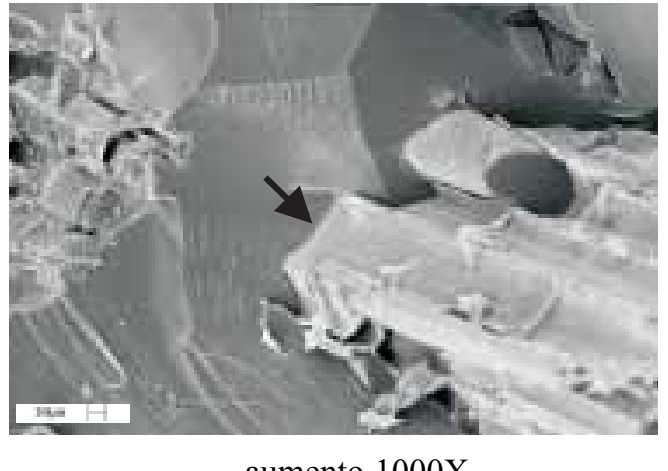

aumento $1000 \mathrm{X}$

(a)

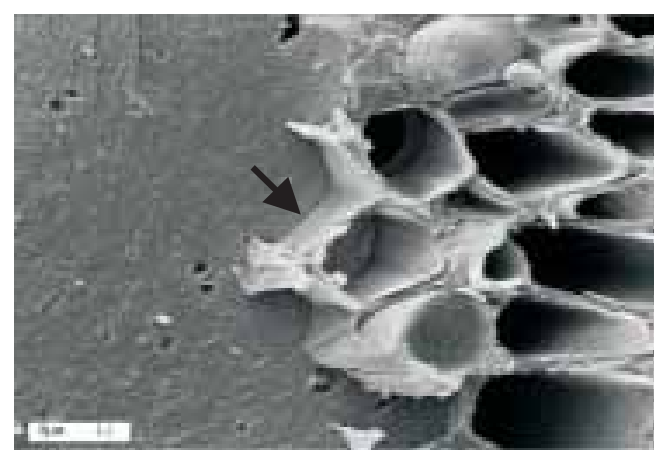

aumento $1000 \mathrm{X}$

(b)

Figura 8. Fotomicrografias das superfícies de fratura dos compósitos (a) fenólico e (b) lignofenólico reforçados com fibras de bagaço submetidas a tratamento com ar ionizado.

para os compósitos contendo bagaço tratado com ar ionizado, pois aparentemente este tratamento preservou a estrutura química das fibras.

\section{Absorção de Água}

As hemiceluloses são consideradas como as principais responsáveis pela absorção de água, embora celulose não cristalina e lignina também desempenhem papel importante neste processo. A umidade intumesce a parede celular da fibra lignocelulósica, até a sua saturação com água. Então, a água passa a ocupar os espaços livres entre os feixes de fibras e esta água livre não intumesce ainda mais a parte interna dos feixes de fibras ${ }^{[32]}$.

Esta análise foi feita em duplicata sendo que a diferença entre as medidas situa-se no intervalo de $0,01 \%$ a $0,6 \%$. Em nenhum caso o erro aproximou as medidas dos diferentes compósitos analisados, o que permite a discussão feita a seguir. Destaca-se que as barras de erros não foram indicadas a fim de não prejudicar a comparação entre as diversas curvas. 
Os compósitos fenólicos contendo bagaço (Figuras 9 e 10) apresentaram menor porcentagem de absorção de água do que os compósitos lignofenólicos (Figura 11), provavelmente devido à presença de grupos polares na lignina contida na matriz lignofenólica, os quais aumentam a higroscopicidade da matriz.

Os ensaios de absorção de água, mostrados na Figura 9, revelam que o compósito fenólico com fibras de bagaço não tratadas apresentou uma maior velocidade de absorção de água no início, até aproximadamente a $3^{\mathrm{a}}$ semana. A introdução das fibras aumenta a porcentagem de água absorvida quando comparada ao termofixo, conforme esperado devido à higroscopicidade das fibras.

Comparando-se os resultados obtidos para os compósitos estudados, observa-se que o tratamento com soluções de $\mathrm{NaOH}$ (Figura 9) diminuiu a absorção de água, com destaque para o compósito reforçado com fibras tratadas com solução $8 \%$ de $\mathrm{NaOH}$, que revelou valores inferiores de absorção de água, em relação aos compósitos com fibras não tratadas; tratadas com as diferentes concentrações de soluções alcalinas e também com relação ao compósito com fibras tratadas com ar ionizado. Dentre os fatores que podem ter levado a esta diferença, pode-se destacar que provavelmente a extração de hemicelulose, devido ao tratamento com a solução $8 \%$ de $\mathrm{NaOH}$, deve ser um dos responsáveis por esta diferença, visto que conforme mencionado anteriormente, a hemicelulose é considerada a principal responsável pela absorção de água, por ser mais acessível que as regiões cristalinas da celulose.

Por extrapolação do que foi considerado no parágrafo anterior, seria esperado que o compósito reforçado com fibras tratadas com $\mathrm{NaOH} 10 \%$ apresentasse absorção de água comparável ao compósito em que a fibra foi tratada com $\mathrm{NaOH} 8 \%$, já que os dados da Figura (3.b) mostram que ambas as fibras tiveram os conteúdos de hemicelulose reduzidos e similares, após o tratamento com o álcali. No entanto, após 2,2 semanas, observou-se que o compósito reforçado cujas fibras foram tratadas com solução $10 \%$ de $\mathrm{NaOH}$ apresentou maior absorção de água frente ao compósito reforçado com fibras tratadas com solução $8 \%$ de $\mathrm{NaOH}$. Os índices de cristalinidade de algumas destas fibras de bagaço de cana foram determinados por Difração de raios-X e os resultados revelaram que o tratamento com a solução mais concentrada $(10 \% \mathrm{NaOH})$ leva a fibras com menor índice de cristalinidade (50\%) quando comparada às

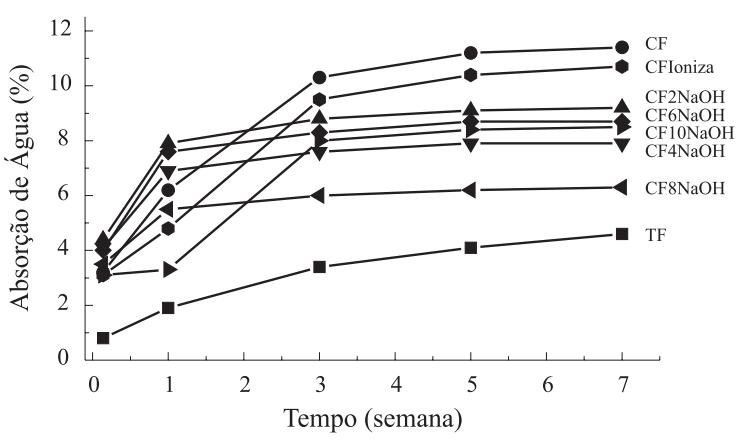

Figura 9. Absorção de água em função do tempo, sendo: TF - termofixo fenólico; $\mathrm{CF}$ - compósito fenólico com fibras de bagaço de cana apenas extraídas; CF2NaOH, CF4NaOH, CF6NaOH, CF8NaOH e CF10NaOH - compósitos fenólicos com fibras de bagaço de cana tratadas com soluções 2, 4, 6, 8 e 10\% de $\mathrm{NaOH}$; CFIoniza - compósito fenólico com fibras de bagaço de cana tratadas com ar ionizado.

celuloses das fibras tratadas com as soluções 2 e $6 \%$ de $\mathrm{NaOH}$, iguais a 54 e $55 \%$ respectivamente ${ }^{[20]}$. Sabese que, nas regiões cristalinas, o acesso de reagentes aos grupos hidroxila das fibras lignocelulósicas é dificultado em relação às regiões não cristalinas. Provavelmente, o menor índice de cristalinidade, obtido pelas fibras de bagaço de cana tratadas com solução $10 \%$ de $\mathrm{NaOH}$, pode ter facilitado o acesso da água às regiões não cristalinas, aumentando a absorção de água observada para o compósito fenólico reforçado com esta fibra.

Por outro lado, este resultado de menor absorção de água quando a fibra é tratada com álcali, também pode ser relacionado às propriedades da interface fibra/matriz. Nesta região, quanto maior o número de microvazios presentes, originados por uma adesão ineficiente, maior o número de agrupamentos de moléculas de água presentes ${ }^{[33]}$. Conforme já mencionado na análise dos resultados obtidos por MEV, o

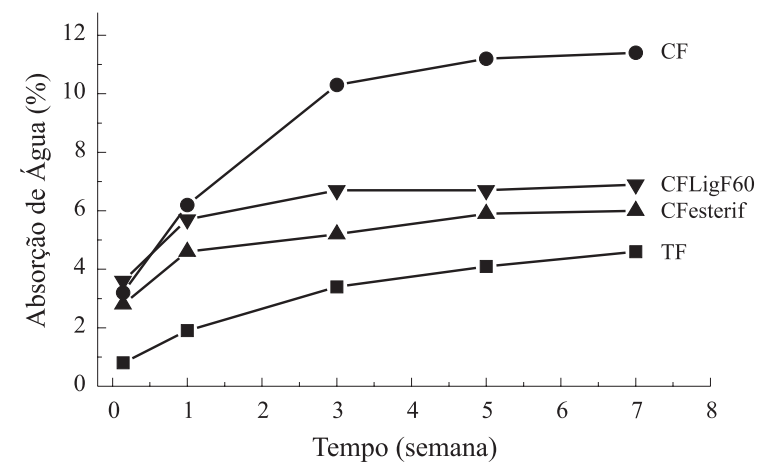

Figura 10. Absorção de água em função do tempo, sendo: TF - termofixo fenólico; CF - compósito fenólico com fibras de bagaço de cana apenas extraídas; CFesterif - compósito fenólico com bagaço de cana tratado com solução $10 \%$ de $\mathrm{NaOH}$ e esterificado com anidrido succínico por 24 h; CFLig60 - compósito fenólico com fibras de bagaço de cana modificadas com lignina hidroximetiladas (tempo de reação $=60 \mathrm{~min}$ ). 
tratamento com álcali melhora a adesão fibra/matriz. Este tratamento origina sítios adicionais de interações, já que desagrega as fibras, viabilizando uma maior interpenetração fibra/matriz na superfície ${ }^{[28]}$, diminuindo portanto o número de microcavidades presentes e então diminuindo também a quantidade de agregados de moléculas de água que poderiam estar contidos nestes vazios.

A Figura 11 mostra que tanto a esterificação, como o enriquecimento do conteúdo de lignina na superfície da fibra, promovem uma diminuição na absorção de água, com relação ao compósito reforçado com fibras não tratadas. Nos dois casos, a adesão fibra-matriz mais eficiente deve contribuir para este resultado. No caso das fibras que reagiram com lignina hidroximetilada, o caráter apolar dos múltiplos anéis aromáticos presentes nesta macromolécula, também deve estar contribuindo para a menor absorção de água.

Para os compósitos lignofenólicos (Figura 11), destaca-se o comportamento do compósito esterificado durante $24 \mathrm{~h}$, o qual apresenta absorção de água próxima à do termofixo. Nesta reação com anidrido succínico, a abertura do anel leva à introdução de grupos carboxílicos na superfície da fibra (Figura 1). Estes grupos podem estabelecer fortes ligações de hidrogênio com grupos funcionais da matriz fenólica, aumentando a adesão fibra/matriz, diminuindo, portanto, o número de cavidades que poderiam alojar moléculas de água.

A partir da $3^{\text {a }}$ semana, a absorção de água dos compósitos reforçados com fibras tratadas com ar ionizado, foi praticamente igual àquela dos compósitos reforçados com fibras não tratadas.

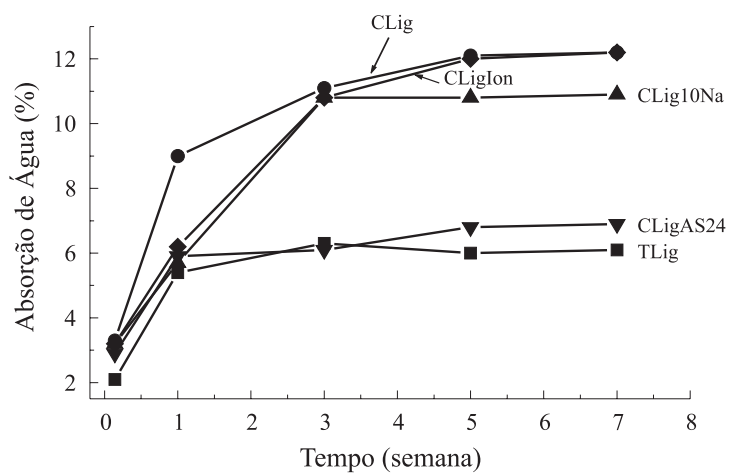

Figura 11. Absorção de água em função do tempo, sendo: TLig termofixo lignofenólico; CLig - compósito lignofenólico com fibras de bagaço apenas extraídas; CLig10 Na - compósito lignofenólico com fibras de bagaço tratadas com solução $10 \%$ de $\mathrm{NaOH}$; CLigAS24 compósito lignofenólico com bagaço tratado com solução $10 \%$ de $\mathrm{NaOH}$ e esterificado com anidrido succínico por $24 \mathrm{~h}$; CLigIon - compósito lignofenólico com fibras de bagaço tratadas com ar ionizado.

\section{Conclusões}

No geral, conforme foi observado pelas imagens de MEV, os tratamentos químicos promoveram melhoria da adesão na interface fibras/matriz. No entanto, como alguns tratamentos levaram à extração de componentes da fibra, alterando propriedades mecânicas da mesma, a resistência ao impacto do compósito diminuiu, em alguns casos.

Os resultados indicam que a lignina pode substituir parcialmente o fenol na preparação de matrizes fenólicas, sem que haja prejuízo para a propriedade de resistência ao impacto. A desvantagem, refere-se à absorção de água, que aumenta quando a lignina está presente. Destacase, no entanto, que a variação observada não foi muito significativa, ou seja, a maior absorção de água quando a lignina está presente na formulação da matriz não inviabiliza a sua utilização nesta aplicação.

Considerando-se os resultados dos ensaios de impacto e das análises morfológicas viabilizadas pelas imagens obtidas via MEV, pode-se destacar os resultados obtidos pelo tratamento das fibras com ar ionizado, principalmente o compósito lignofenólico/ bagaço tratado com ar ionizado. Provavelmente, este tratamento melhorou a adesão do tipo mecânica (em algumas regiões) durante o processo de impregnação das fibras com a matriz lignofenólica, o que está ligado também à desagregação de fibras que este tratamento provocou. Deve-se ressaltar a importância destes resultados, pois a desagregação de fibras é normalmente promovida por tratamento com álcali, que é um método que apresenta desvantagens em relação ao tratamento com ar ionizado, pois:

- o tratamento com ar ionizado não envolve a utilização de solução aquosa alcalina, como no caso do tratamento com solução de $\mathrm{NaOH}$, que implica em necessidade de posterior remoção de $\mathrm{NaOH}$ e, o que é mais importante, eliminação de água, o que é sempre problemático, tendo em vista o caráter hidrofílico das fibras. O tratamento com ar ionizado é feito por "via seca".

- o tratamento com $\mathrm{NaOH}$ promove extração de hemicelulose e lignina, o que altera as propriedades mecânicas das fibras, tornando-as, em alguns casos, menos adequada para utilização como reforço. Os resultados que se tem até o momento não indicam extração de componentes da fibra lignocelulósica, quando a mesma é tratada com ar ionizado. 
Os tratamentos com $\mathrm{NaOH}$ e as modificações químicas com anidrido succínico e lignina/formaldeído das fibras de bagaço, não levaram a uma melhora na performance dos compósitos finais, no que se refere à propriedade de resistência ao impacto. No entanto, as imagens obtidas via MEV revelaram uma interpenetração mais eficiente da matriz no feixe de fibras. No que se refere à absorção de água por parte dos compósitos, o tratamento das fibras com álcali levou a melhores resultados, quando comparados com o tratamento com ar ionizado, pelo menos para este tempo de tratamento considerado.

\section{Agradecimentos}

Os autores agradecem à FAPESP, pelo apoio financeiro e pelas bolsas de doutorado e mestrado concedidas a Jane M. F de Paiva e Sandra P. S. Tita; ao Prof. Dr Elias Hage Jr (DEMa/UFSCar) pela realização dos ensaios de impacto.

\section{Referências Bibliográficas}

1. Paiva, J. M. F.; Silva, S. P.; Tanaka, I. A.; Trindade, W. G.; Angelucci, C. A. \& Frollini, E. - "Impact Strength of Phenolic Matrices Reinforced with Lignocellulosic Material”, in: Mattoso, L. H. C.; Leão, A.; Frollini, E., eds. Natural Polymers and Composites, p.460-8 (2000).

2. Paiva, J. M. F. \& Frollini, E. - "Natural Fibers Reinforced Thermoset Composites”, in: Frollini, E.; Leão, A.; Mattoso, L. H. C., eds. Natural Polymers and Agrofibers Based Composites, p.229-55 (2000).

3. Paiva, J. M. F.; Trindade, W. G. \& Frollini, E. Polímeros: Ciência e Tecnologia, 4, p.170-6 (1999).

4. Leão, A. L.; Tan, I. H.; Caraschi, J. C. - “Curaua Fiber - A Tropical Natural Fiber from Amazons Potential and Applications in Composites", in: International Conference on Advanced Composites, Hurghada-Egypt, 15-8 dez. (1998).

5. Savastano Jr., H.; Warden, P. G. \& Coutts, R. S. P. - Cement \& Concrete Composites, 22, p.37984 (2000).

6. Bledzki, A. K. \& Gassan, J. - Prog. Polym. Sci., 24, p. 221-74 (1999).
7. Agarwal, R.; Saxena, N. S.; Sharma, K. B; Thomas, S. \& Sreekala, M. S. - Materials Science \& Engineering, A277, p.77-82 (2000).

8. Canché-Escamilla, G.; Cauich-Cupul, J. I.; Mendizábal, E.; Puig, J. E.; Vázquez-Torres, H. \& Herrera-Franco, P. J. - Composites: Part A, 30, p.349-59 (1999).

9. Rowell, R. M.; Han, J. S. \& Rowell, J. S. - "Natural Polymers and Agrofibers Based Composites”, USP/Unesp/Embrapa, p.115-34, São Carlos (2000).

10. Gellersted, F. \& Gatenholm, P. - Cellulose, 6, p.103-21 (1999).

11. Kuzak, S, G.; Hiltz, J. A. \& Waitkus, P. A. - J. Appl. Polym. Sci., 67, p.349-61 (1998).

12. Hull, D. - "An Introduction to Composites Materials”, Cambridge University Press, p.37-42, New York (1981).

13. Tjong, S. C.; Xu, Y. \& Meng, Y. Z. - J. Appl. Polym. Sci., 72, p.1647-53 (1999).

14. Caraschi, J. C. - "Estudo das Relações Estrutura/ Propriedades de Carboximetilcelulose Obtida por Derivatização de Polpa de Bagaço de Canade-Açúcar", Tese de Doutorado, Universidade de São Paulo, Brasil (1997).

15. Danielson, B.; Simonson, R. - J. Adhes. Sci, Tecnol., 12(9), p.923-39 (1998).

16. Vázques, G.; González, S.; Freire, S. \& Antorrera, G. - Bioresour. Technol., 60, p.191-8 (1997).

17. Campana Fo, S. P. C.; Frollini, E.; Curvelo, A. A. S. - "Organosolv Delignification of Lignocellulosic Materials: Preparation and Caracterization of Lignin and Cellulose Derivatives", in: Leão, A. L.; Carvalho, F. X; Frollini, E., eds. Lignocellulosic-Plastics Composites, p.163-78 (1997).

18. Pimenta, M. J. A. \& Frollini, E. - "Anais da Associação Brasileira de Química”,46(1), p.439 (1997).

19. Pimenta, M. J. A. - "Lignina em Resinas Fenólicas do Tipo Resol”, Dissertação de Mestrado, Universidade de São Paulo, Brasil (1995). 
20. Paiva, J. M. F. - “Compósitos de Matriz Termorrígidas Fenólicas e Lignofenólicas Reforçadas com Fibras Vegetais", Tese de Doutorado, Universidade de São Paulo, Brasil (2001).

21. Paiva, J. M. F \& Frollini, E. - J. Appl. Polym. Sci., 83, p.880-8 (2002).

22. American Society for Testing and Materials. ASTM D256 - "Standard Test Methods for Determination the Pendulum Impact Resistence of Notched Specimens of Plastics”, (CD ROM), Philadelphia (1993).

23. American Society for Testing and Materials. ASTM D570 - "Standard Test Methods for Water Absorption of Plastics", (CD ROM), Philadelphia (1988).

24. Kharade, A. Y \& Kale, D. D. - Eur. Polym. J., 34(2), p.201-5 (1998).

25. Maldas, D.; Shiraishi, N \& Harada, Y. - J. Adhes. Sci. Technol., 11(3), p.305-16 (1997).

26. Nada, A. M. A.; El-Saied, H.; Fadl, M. H. \& Nasar, M. A. - Polym. - Plast. Technol. Eng., 33(4), p.515-36 (1994).
27. Ray, D.; Sarkar, B. K.; Rana, A. K. \& Bose, N. R. - Composites, Part A, 32, p.119-27 (2001).

28. Mohanty, A. K.; Khan, M. A. \& Hinrichsen, G. Composites Part A: Applied Science and Manufacturing, 31, p.143-50 (2000).

29. Stamboulis, A.; Baillie, C. A. \& Peijs, T. - Composites, Part A: Appl. Sci. Manufact.,32, p.1105-15 (2001).

30. Sawyer, L. C. \& Grubb, D. T. - "Polymer Microscopy”, Chapman and Hall, London, p.134 e 219 (1994).

31. Triana, O.; Leonard, M.; Saavedra, F.; Fernández, N.; Gálvez, G. \& Peña, E.- "Atlas del Bagazo de la Caña de Azucar”,Cuba-9/GEPLACEA/ ICIDCA, México (1990).

32. Das, S.; Saha, A. K. Choudhury, P. K.; Basak, R. K.; Mitra, B. C.; Todd, T. \& Lang, S. - J. Appl. Polym. Sci., 76, p.1652-61 (2000).

33. Anglès, M. N.; Salvadó, M. N. \& Dufresne, A. J. Appl. Polym. Sci., 74, p.1962-77 (1999).

Recebido: 09/10/01

Aprovado: 05/08/02 